\title{
Performance of the Transverse Oscillation method using beamformed data from a commercial scanner
}

Pihl, Michael Johannes; Nikolov, S.; Haugaard, P.; Hemmsen, Martin Christian; Jensen, Jørgen Arendt

Published in:

2009 IEEE International Ultrasonics Symposium (IUS)

Link to article, DOI:

10.1109/ULTSYM.2009.5441954

Publication date:

2009

Document Version

Publisher's PDF, also known as Version of record

Link back to DTU Orbit

Citation (APA):

Pihl, M. J., Nikolov, S., Haugaard, P., Hemmsen, M. C., \& Jensen, J. A. (2009). Performance of the Transverse Oscillation method using beamformed data from a commercial scanner. In 2009 IEEE International Ultrasonics Symposium (IUS) IEEE. https://doi.org/10.1109/ULTSYM.2009.5441954

\section{General rights}

Copyright and moral rights for the publications made accessible in the public portal are retained by the authors and/or other copyright owners and it is a condition of accessing publications that users recognise and abide by the legal requirements associated with these rights.

- Users may download and print one copy of any publication from the public portal for the purpose of private study or research.

- You may not further distribute the material or use it for any profit-making activity or commercial gain

- You may freely distribute the URL identifying the publication in the public portal 


\title{
Performance of the Transverse Oscillation Method using Beamformed Data from a Commercial Scanner
}

\author{
Michael Johannes Pihl ${ }^{1}$, Svetoslav Nikolov ${ }^{2}$, Per Haugaard ${ }^{2}$, Martin Christian Hemmsen ${ }^{1,2}$, and \\ Jørgen Arendt Jensen ${ }^{1}$ \\ ${ }^{1}$ Center for Fast Ultrasound Imaging, Department of Electrical Engineering, \\ Technical University of Denmark, DK-2800 Kgs. Lyngby, Denmark \\ ${ }^{2}$ BK Medical ApS, Mileparken 34, DK-2730 Herlev, Denmark
}

\begin{abstract}
Blood velocity estimates using conventional color flow imaging (CFI) or Doppler techniques are angle dependent. One of the proposed techniques to overcome this limitation is the Transverse Oscillation (TO) method, which also estimates the lateral velocity components. The performance of this is evaluated on a commercial platform. Beamformed data are acquired using a commercial BK Medical scanner as opposed to the previously reported results obtained with the experimental scanner RASMUS. The implementation is evaluated using an in-house circulating flow rig by calculating the relative mean standard deviation and bias of the velocity components. The relative mean standard deviation decreases as the number of shots per estimate increases and a value of $5 \%$ is obtained for 64 shots per estimate. For a center frequency of $5 \mathrm{MHz}$ at $60^{\circ}$, $75^{\circ}$, and $90^{\circ}$, the relative mean bias varies from $21 \%$ to $27 \%$ and is lowest at a transmit focal depth close to the center of the vessel. The present performance is comparable with the results from the experimental scanner and simulations. It is obtained with only few changes to the conventional CFI setup and further optimization can improve the performance. This illustrates the feasibility of implementing the TO method on a commercial platform for real-time estimation.
\end{abstract}

\section{INTRODUCTION}

Medical ultrasound is widely used to study blood flow dynamics in the human circulatory system. For instance, the estimation of blood flow velocities plays a key role in diagnosing major diseases in the carotid arteries [1]. However, blood velocity estimates using conventional color flow imaging (CFI) or Doppler techniques are angle dependent. That is a major limitation, and poses a huge challenge for quantitatively estimating the magnitude of the blood velocity. Present conventional techniques for estimating the magnitude of the velocity (as in spectral Doppler) are based on operator-based angle estimations, yet it is often difficult to predict flow direction and compensate for it [2]. It also strongly limits the possibility of visualizing complicated flow patterns like disturbed flow and vortices [3], which potentially carry pathological information about e.g. stenoses and malfunctioning valves.

Several techniques have been proposed to compensate for the inherent angle dependency problem. Fox [4] suggested a multibeam method, Trahey et al. [5] a speckle tracking technique, Newhouse et al. [6] an approach based on the transit-time spectral broadening effect, and Bonnefous [7] suggested using a number of beamformers working in parallel. Another method is the directional beamforming suggested by Jensen [8] or the Plane Wave Excitation method as recently suggested by Udesen et al. [9]. Another recent method using a cross correlation approach was proposed by Henze et al. [10]. Most of the above mentioned techniques have limitations in either geometry, computational load of the estimator, inherent noise, or heavy computational demands on beamformation.

Jensen and Munk [11] suggested the Transverse Oscillation (TO) method. Anderson [12] suggested a similar approach. The TO method has demonstrated promising in vivo results [13], [14]. However, the previously reported results have been obtained uing the experimental scanner RASMUS [15], [16].

The purpose of this paper is to demonstrated the feasibility of a commercial implementation of the TO method for clinical use. The implementation is tested in a flow rig with a parabolic flow profile. Statistical measures are computed to evaluate and compare the performance to previously reported results with focus on the lateral velocity component.

The following section describes the methods employed, and the results are presented and discussed in Section III.

\section{Methods}

\section{A. TO implementation}

The basic idea in the TO method is to create a double oscillating field by using special apodization profiles in receive. Two lines with a lateral displacement of a quarter spatial wavelength, corresponding to a $90^{\circ}$ phase shift, are beamformed simultaneously in receive. A center line is also beamformed for traditional axial velocity estimation. For a description and derivation of the estimator, the reader is referred to Jensen [17].

Beamformed data are acquired using a BK Medical (Herlev, Denmark) 2202 Pro Focus scanner, a BK8812 linear array transducer, and a BK UA2227 research interface connected to a standard PC through a DALSA (Waterloo, ON, Canada) X64-CL Express camera link. Only minor changes to the conventional CFI setup, including adjusting the apodization and delay profiles in receive, are necessary to obtain the required data. 

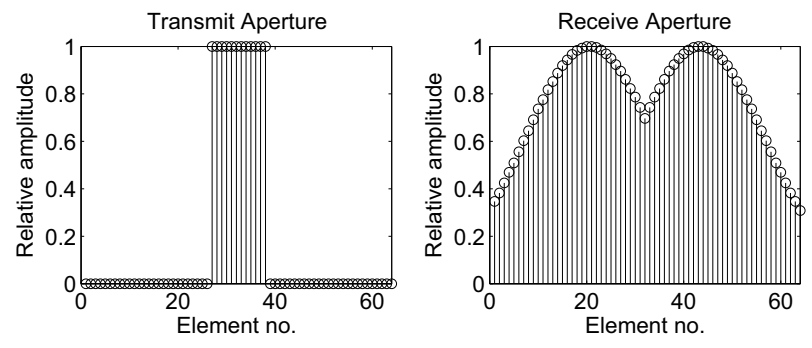

Fig. 1. The transmit and receive aperture for the TO estimator with a transmit focal depth at $15 \mathrm{~mm}$. The transmit aperture is rectangular, and the F-number is 4 . The receive aperture is the TO apodization.
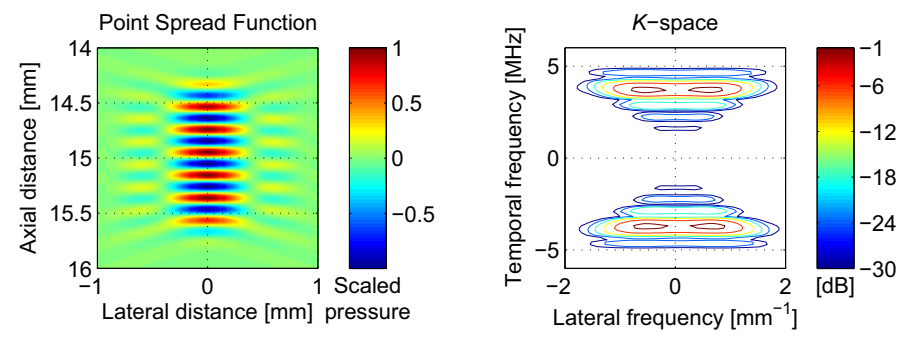

Fig. 2. The pulse-echo field (or point spread function) at the focal depth calculated based on the used transmit and receive apertures (left). The 2DFourier transform of the pulse-echo field, i.e. $k$-space representation (right)

The transmit and receive aperture functions used in this paper are illustrated in Fig. 1. A narrow transmit aperture produces a broad transmit field. The relative high apodization values in the receive aperture increases the signal-to-noiseratio (SNR). The point spread function (PSF) is calculated using Field II [18], [19] and is depicted in Fig. 2, which also illustrates the 2D-Fourier transform of the pulse echo-field, i.e. the $k$-space representation. From Fig. 2 it can be noted that the transverse oscillations are $14 \mathrm{~dB}$ lower compared to the main lobe. They are lower compared to the ones presented by Udesen et al. [13], [14] where side lobes were around $2 \mathrm{~dB}$ down. This can also be observed from the $k$-space representation where the distinction of the two lateral peaks is poorer. The differences in PSFs affects the estimator.

Due to limitations in the current scanner setup, the TO apodization profile is kept constant over depth. This increases the spatial wavelength over depth. Therefore, the lateral velocity sensitivity changes over depth. This poses an optimization challenge, but does not affect the proof of concept.

The parameters for the measurements are shown in Table I. The table includes the physical setup of the flow rig, fixed scanner parameters, and the parameters that were varied in this study.

\section{B. Flow rig setup}

Velocity measurements are performed using an in-house circulating flow rig to evaluate the TO method. The setup consists of a long rigid tube replaced by a rubber tube inside a water filled container as illustrated in Fig. 3. The tube is filled with a blood mimicking fluid [13]. A Cole-Parmer (Vernon Hills, IL) 75211-60 centrifugal pump controls the fluid flow,
TABLE I

PARAMETERS FOR THE EXPERIMENTAL FLOW RIG MEASUREMENTS. VALUES MARKED WITH BOLD FACE DENOTES THE REFERENCE SETUP.

\begin{tabular}{|c|c|}
\hline Flow Rig Setup & Value \\
\hline Vessel radius & $5.7 \mathrm{~mm}$ \\
\hline Center of vessel & $16 \mathrm{~mm}$ \\
\hline Peak velocity of flow, $v_{0}$ & $0.215 \mathrm{~m} / \mathrm{s}$ \\
\hline Fixed Scanner Parameters & Value \\
\hline Distance between aperture peaks & $6.6 \mathrm{~mm}$ \\
\hline Pulse repetition frequency & $1.3 \mathrm{kHz}$ \\
\hline Speed of sound & $1480 \mathrm{~m} / \mathrm{s}$ \\
\hline Averaging length & 1 pulse length $(2.4 \mathbf{~ m m})$ \\
\hline Number of transmit cycles & 6 \\
\hline Transverse lag & 1 \\
\hline Varied Scanner Parameter & Value \\
\hline Number of shots per estimate & {$\left[\begin{array}{lllll}4 & 8 & 16 & 31 & 61\end{array}\right]$} \\
\hline Transmit focus depth & {$\left[\begin{array}{lllll}10 & 15 & 20 & 25 & 30\end{array}\right] \mathrm{mm}$} \\
\hline Beam-to-flow angle & {$\left[\begin{array}{lll}60 & 75 & 90\end{array}\right]^{\circ}$} \\
\hline Center frequency of CFI pulses & {$\left[\begin{array}{ll}3.75 & 5\end{array}\right] \mathrm{MHz}$} \\
\hline
\end{tabular}

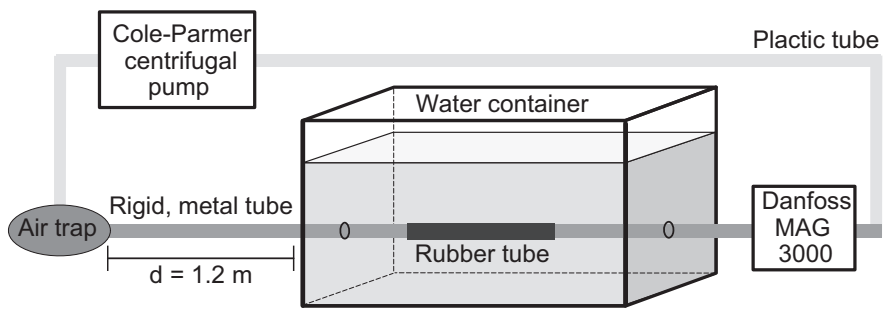

Fig. 3. The flow rig setup with a Cole-Parmer centrifugal pump, an air entrapment device, a water container with a rubber tube, and a Danfoss MAG 3000 magnetic flow meter. Notice that this figure is not to scale, and that the entrance length of the tube is more than $1.2 \mathrm{~m}$, enough to ensure fully developed laminar flow. A fixture can be placed in the water container to keep the transducer fixed at a known beam-to-flow angle.

and a Danfoss (Sønderborg, Denmark) MAG 3000 magnetic volume flow meter is used to measure the actual volume flow. The transducer can be placed in a fixture and the beam-to-flow angle can be set to a known value. The fixture can then be placed in the water container prior to the measurements.

\section{Statistics}

To investigate the performance of the method, a statistical analysis is performed on the data collected from the flow rig setup. It is assumed that the velocity estimates are independent between depths and between velocity profiles, and that the volume flow is constant over a measurement sequence.

At each discrete depth in the vessel, the velocity is estimated from a number of emissions. The average, $\bar{v}\left(z_{k}\right)$, of $N$ estimates and the estimated standard deviation, $\sigma\left(z_{k}\right)$, is calculated at each discrete depth as

$$
\begin{aligned}
\bar{v}\left(z_{k}\right) & =\frac{1}{N} \sum_{i=1}^{N} v_{i}\left(z_{k}\right) \\
\sigma\left(z_{k}\right) & =\sqrt{\frac{1}{N-1} \sum_{i=1}^{N}\left(v_{i}\left(z_{k}\right)-\bar{v}\left(z_{k}\right)\right)^{2}},
\end{aligned}
$$



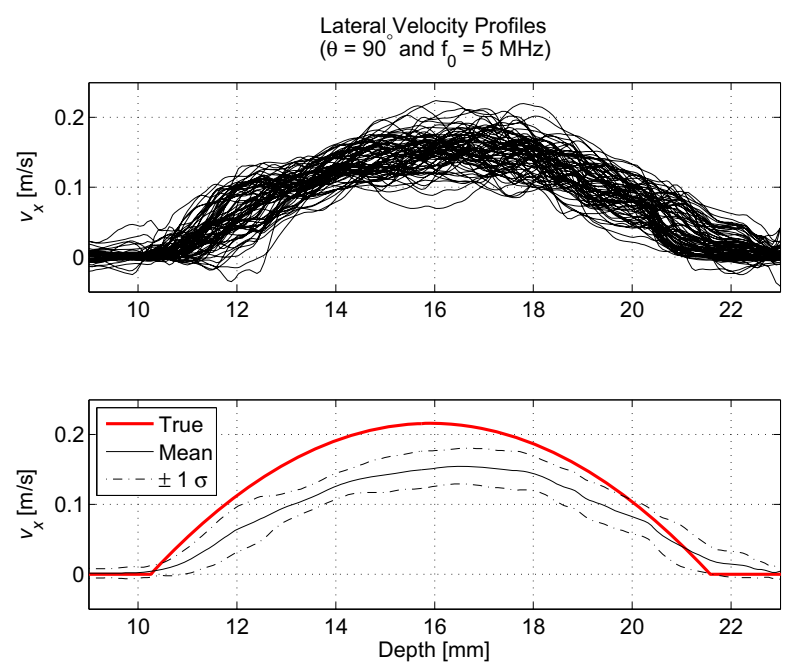

Fig. 4. TO estimated lateral velocities for 75 flow profiles with a beam-toflow angle of $90^{\circ}$ and a center frequency of $5 \mathrm{MHz}$ (top). Mean estimate \pm one standard deviation and expected theoretical velocity profile. No attempt has been made to suppress false velocity estimates at the vessel wall and in the surrounding water (bottom). Here, $\tilde{B}_{v_{x}}$ is $21 \%$ and $\tilde{\sigma}_{v_{x}}$ is $11 \%$.

where $v_{i}\left(z_{k}\right)$ is the $i$ th velocity estimate at the discrete depth $z_{k}$.

To determine the accuracy of the method, the bias, $B$, between the mean estimated velocity and the expected velocity, $v_{\mu}\left(z_{k}\right)$, at each depth can be calculated as

$$
B=\bar{v}\left(z_{k}\right)-v_{\mu}\left(z_{k}\right) .
$$

For better and more straightforward comparison of various parameter settings, two single measures for the bias and the estimated standard deviation for a specific velocity profile are preferred. In order to do so, the estimated variance and the absolute bias are averaged over the entire vessel and divided by the peak velocity, $v_{0}$. The two quantities, the relative mean absolute bias, $\tilde{B}$, and the estimated relative mean standard deviation, $\tilde{\sigma}$, are given by

$$
\begin{aligned}
\tilde{B} & =\frac{1}{v_{0} \cdot N_{z_{k}}} \sum_{z_{k}=1}^{N_{z_{k}}}\left|B\left(z_{k}\right)\right| \\
\tilde{\sigma} & =\frac{1}{v_{0}} \sqrt{\frac{1}{N_{z_{k}}} \sum_{z_{k}=1}^{N_{z_{k}}} \sigma\left(z_{k}\right)^{2}},
\end{aligned}
$$

where $N_{z_{k}}$ is the number of discrete samples within the vessel. These measures can be used to describe the performance of the TO estimator.

\section{RESULTS AND DisCUSSION}

To address the feasibility of a commercial implementation of the TO method, the obtained results are compared with those from a simulation study and from the experimental scanner RASMUS, as previously reported [13], [20]. However, some parameters as well as the reference setup from the present study differ from the previous investigations.

Fig. 4 shows the estimated lateral velocity component of the flow profiles for 75 measurements at a beam-to-flow angle
Number of Shots per Estimate
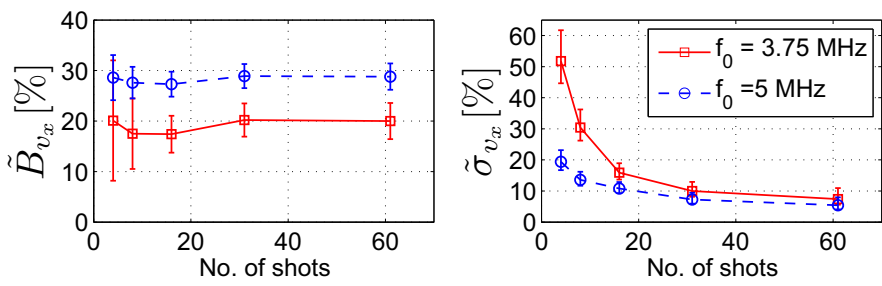

Fig. 5. The relative mean estimated bias, $\tilde{B}_{v_{x}}$, and relative mean estimated standard deviation, $\tilde{\sigma}_{v_{x}}$, for the lateral velocity component for center frequencies of 3.75 and $5 \mathrm{MHz}$. The error bars indicate the $95 \%$ confidence interval on $\tilde{B}_{v_{x}}$ and $\tilde{\sigma}_{v_{x}}$, respectively.

Transmit Focus
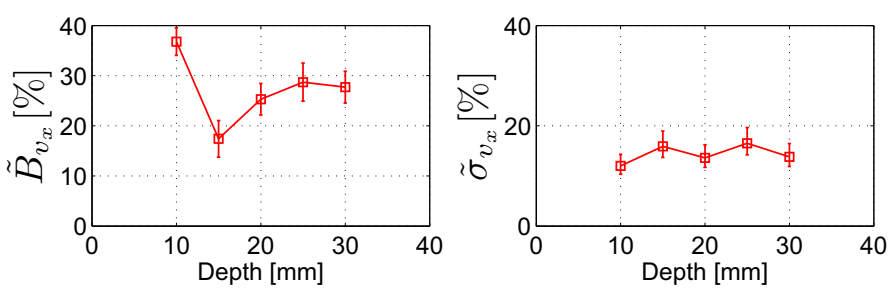

Fig. 6. $\tilde{B}_{v_{x}}$ and $\tilde{\sigma}_{v_{x}}$ for the lateral velocity component as a function of transmit focal depth $(N=75)$.

of $90^{\circ}$ and at a center frequency of the transmitted pulse of $5 \mathrm{MHz}$. It also indicates the mean estimate \pm one standard deviation and the expected true velocity. The TO method is clearly able to estimate the lateral velocity component, which is not possible with conventional estimators. As expected, the estimated lateral velocity profile has a parabolic shape. However, the TO estimator underestimates the velocity. With the parameter settings given in Table I the relative mean bias, $\tilde{B}_{v_{x}}$, is $21 \%$ and the relative standard deviation, $\tilde{\sigma}_{v_{x}}$, is $11 \%$.

\section{A. Number of shots per estimate}

When the number of shots per estimate is increased, $\tilde{\sigma}_{v_{x}}$ decreases, as expected, with approximately $\sqrt{N}$ as illustrated in Fig. 5. $\tilde{\sigma}_{v_{x}}$ is lower for $5 \mathrm{MHz}$ than for $3.75 \mathrm{MHz}$. Conversely, $\tilde{B}_{v_{x}}$ is more or less constant, and somewhat larger for $5 \mathrm{MHz}$ than for $3.75 \mathrm{MHz}$.

The results for the relative bias and standard deviation, when increasing the number of shots per estimate, show the same trend as the previously reported simulations [13]. The simulation results have lower values, but they are simulated with an infinite SNR, which is not the case in a real measurement situation. At 32 shots per estimate the simulated results had a relative standard deviation of $6 \%$ at $70^{\circ}$, where this study showed values of $7 \%$ and $10 \%$ at $75^{\circ}$ with center frequencies at $5 \mathrm{MHz}$ and $3.75 \mathrm{MHz}$, respectively. This demonstrates a similar performance, where it should be noted that the simulated results were obtained with a center frequency of $7 \mathrm{MHz}$ and a different PSF.

\section{B. Transmit focus}

Varying the transmit focus from 10 to $30 \mathrm{~mm}$ in $5 \mathrm{~mm}$ increments yields the results shown in Fig. 6, where the F- 
Beam to Flow Angle and Center Frequency
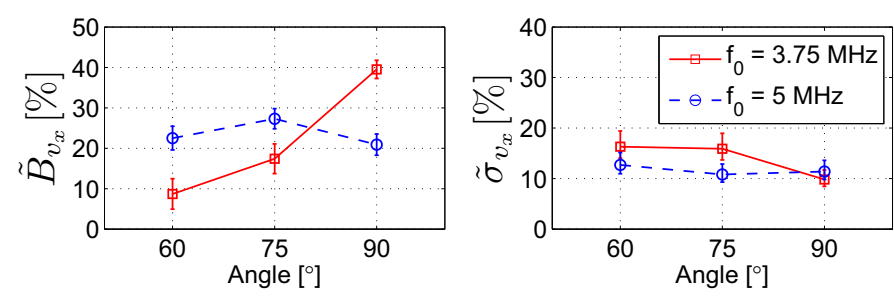

Fig. 7. $\tilde{B}_{v_{x}}$ and $\tilde{\sigma}_{v_{x}}$ as a function of beam-to-flow angle and for center frequencies of 3.75 and $5 \mathrm{MHz}(N=75)$.

number is held constant at 4.0. $\tilde{B}_{v_{x}}$ has a minimum at $15 \mathrm{~mm}$ of $17 \%$, whereas $\tilde{\sigma}_{v_{x}}$ shows no clear significant variation.

The obtained results for changing the transmit focus depth, show that for the given setup and a specific vessel location, the lowest bias is obtained with a focus depth of $15 \mathrm{~mm}$. The $15 \mathrm{~mm}$ is close to the center of the vessel at $16 \mathrm{~mm}$.

Comparing the results for different transmit focal depths with the simulations, the trends in the results are comparable. The optimal depth is a trade off between having a relative broad lateral extend when focusing beyond the vessel, and not reducing the SNR by emitting energy over a large area [13].

\section{Beam-to-flow angle}

Measurements were performed at three different beamto-flow angles: $60^{\circ}, 75^{\circ}$, and $90^{\circ}$. The resulting statistical measures are shown in Fig. 7.

For a center frequency at $3.75 \mathrm{MHz}$, the bias increases with increasing angle, whereas the standard deviation slightly decreases. For $5 \mathrm{MHz}$, the bias peaks at $75^{\circ}$, while the standard deviation is constant. A constant bias over the range of angles would be desirable, because it would then be possible to correct for the underestimation with a fixed scaling factor.

The beam-to-flow angle affects the magnitude of the axial and lateral velocity components. It also effects the bias and the standard deviation. The simulation results showed almost constant relative bias from $60^{\circ}$ to $90^{\circ}$, whereas the relative standard deviation dropped from about $7 \%$ to $5 \%$. The flow rig results in Udesen et al. [13] showed the same trend with a relative bias around $10 \%$ and a relative standard deviation from $4-7 \%$ for 32 shots per estimate and a center frequency of $7 \mathrm{MHz}$.

Comparing with the present study, $\tilde{\sigma}_{v_{x}}$ was more or less constant around $11 \%(5 \mathrm{MHz})$, and decreasing from 17 to $10 \%$ for $3.75 \mathrm{MHz}$ both with 16 shots per estimate. This corresponds to the simulations and the results obtained with the experimental scanner, especially when taking the difference in number of shots and the variation in PSFs into account.

\section{CONCLUSION}

The Transverse Oscillation method has been investigated using data from a commercial BK scanner. The implementation was evaluated and the results were compared to previously reported results from an experimental scanner. The results were found comparable having the differences in PSFs in mind. The performance can be improved by introducing a dynamic receive aperture, by further optimizations of the PSF, and a potential bias calibration. Hence, the feasibility of a commercial implementation for real-time estimations of blood flow vector velocity has been demonstrated.

\section{ACKNOWLEDGEMENTS}

This work was supported by grant 26-04-0024 from the Danish Science Foundation and by BK Medical Aps, Denmark.

\section{REFERENCES}

[1] E. G. Grant et al., "Carotid artery stenosis: Gray-scale and doppler us diagnosis - society of radiologists in ultrasound consensus conference," Radiology, vol. 229, no. 2, pp. 340-346, 2003.

[2] D. J. Phillips, K. W. Beach, J. Primozich, and D. E. Strandness, "Should results of ultrasound Doppler studies be reported in units of frequency or velocity?," Ultrasound Med. Biol., vol. 15, pp. 205-212, 1989.

[3] K.L. Hansen, J. Udesen, F. Gran, J. A. Jensen, and M. B. Nielsen, "Invivo examples of flow patterns with a fast vector velocity ultrasound method," Ultraschall in Med., 2009. Accepted for publication.

[4] M. D. Fox, "Multiple crossed-beam ultrasound Doppler velocimetry," IEEE Trans. Son. Ultrason., vol. SU-25, pp. 281-286, 1978.

[5] G. E. Trahey, J. W. Allison, and O. T. von Ramm, "Angle independent ultrasonic detection of blood flow," IEEE Trans. Biomed. Eng., vol. BME-34, pp. 965-967, 1987.

[6] V. L. Newhouse, D. Censor, T. Vontz, J. A. Cisneros, and B. B. Goldberg, "Ultrasound doppler probing of flows transverse with respect to beam axis," IEEE Trans. Biomed. Eng., vol. 34, pp. 779-789, 1987.

[7] O. Bonnefous, "Measurement of the complete (3D) velocity vector of blood flows," in Proc. IEEE Ultrason. Symp., 1988, pp. 795-799.

[8] J. A. Jensen, "Directional velocity estimation using focusing along the flow direction: I: Theory and simulation," IEEE Trans. Ultrason., Ferroelec., Freq. Contr., pp. 857-872, 2003.

[9] J. Udesen, F. Gran, K. L. Hansen, J. A. Jensen, C. Thomsen, and M. B. Nielsen, "Examples of In Vivo blood vector velocity estimation," IEEE Trans. on Ultrason., Ferroelec., Freq. Contr., vol. 55, no. 8, pp. 17291743, 2008.

[10] L. Henze, I. K. Holfort, J. Kortbek, and J. A. Jensen, "Transverse Correlation: An Efficient Transverse Flow Estimator - Initial Results," in Proc. IEEE Ultrason. Symp., 2008, pp. 1619-1622.

[11] J. A. Jensen and P. Munk, "A new method for estimation of velocity vectors," IEEE Trans. Ultrason., Ferroelec., Freq. Contr., vol. 45, pp. 837-851, 1998.

[12] M. E. Anderson, "Multi-dimensional velocity estimation with ultrasound using spatial quadrature," IEEE Trans. Ultrason., Ferroelec., Freq. Contr., vol. 45, pp. 852-861, 1998.

[13] J. Udesen and J. A. Jensen, "Investigation of transverse oscillation method," IEEE Trans. Ultrason., Ferroelec., Freq. Contr., vol. 53, pp. 959-971, 2006.

[14] J. Udesen, M. B. Nielsen, K. R. Nielsen, and J. A. Jensen, "Examples of In Vivo blood vector velocity estimation," Ultrasound in Med. \& Biol., vol. 33, no. 4, pp. 541-548, 2007.

[15] J. A. Jensen, O. Holm, L. J. Jensen, H. Bendsen, H. M. Pedersen, K. Salomonsen, J. Hansen, and S. Nikolov, "Experimental ultrasound system for real-time synthetic imaging," in Proc. IEEE Ultrason. Symp., 1999, vol. 2, pp. 1595-1599.

[16] J. A. Jensen, O. Holm, L. J. Jensen, H. Bendsen, S. I. Nikolov, B. G. Tomov, P. Munk, M. Hansen, K. Salomonsen, J. Hansen, K. Gormsen, H. M. Pedersen, and K. L. Gammelmark, "Ultrasound research scanner for real-time synthetic aperture image acquisition," IEEE Trans. Ultrason., Ferroelec., Freq. Contr., vol. 52 (5), pp. 881-891, May 2005.

[17] J. A. Jensen, "A new estimator for vector velocity estimation," IEEE Trans. Ultrason., Ferroelec., Freq. Contr., vol. 48, no. 4, pp. 886-894, 2001.

[18] J. A. Jensen, "Field: A program for simulating ultrasound systems," Med. Biol. Eng. Comp., vol. 10th Nordic-Baltic Conference on Biomedical Imaging, Vol. 4, Supplement 1, Part 1, pp. 351-353, 1996.

[19] J. A. Jensen and N. B. Svendsen, "Calculation of pressure fields from arbitrarily shaped, apodized, and excited ultrasound transducers," IEEE Trans. Ultrason., Ferroelec., Freq. Contr., vol. 39, pp. 262-267, 1992.

[20] J. Udesen, 2-D blood vector velocity estimation using a phase shift estimator., Ph.D. thesis, Ørsted $\bullet$ DTU, Technical University of Denmark, 2800, Lyngby, Denmark, 2005. 